\title{
EDitorial
}

\section{Half empty or half full?}

\section{Andy Begg}

As we know, a pessimist is someone who sees the glass of wine as half empty while the optimist is someone who sees it as half full. The pessimistic perspective with its emphasis on problems, often gets more attention, and this would be understandable when a new policy such as a curriculum document is released, entailing possible increases in teacher workloads. Yet over the last 12 months I have informally interacted with teachers and colleagues as they commented on the draft curriculum and could not help noticing that many aspects of the draft have stimulated both pessimistic and optimistic reactions.

I tend to side with the teachers who saw new opportunities but I understand the alternative view. Regardless of my bias it seems important to consider both perspectives because implementing a new curriculum, like introducing a new topic in class, involves the change process, and just as a teacher starts where the students are, so a curriculum change agent must start where the teachers are.

From teachers' comments on the Ministry of Education's (2006) draft curriculum (the final version was not released when this editorial went to print) I have identified a number of issues that stimulated contrasting views.

In terms of the vision of the curriculum, the words "entrepreneurial" and "economic well-being" were interpreted as implying a business orientation. While some favoured this, others preferred a concern for sustainability, which they identified as being contradictory. 


\section{Curriculum Matters}

The key competencies were seen by some as being too middle-of-theroad, with terms such as "managing self" and "relating to others" not going as far as self-respect, self-knowledge, personal and social identity, and concern and empathy for others. At the same time, most of the people who made these comments seemed to see the increased emphasis on the personal, social, and cognitive domains as a desirable-if not an essential-broadening of education. The alternative view was that such an emphasis was impractical in our current educational climate, that curriculum content is more important, and that an emphasis on personal and social growth means less time will be available for the content that is needed by students.

The notion of thinking was affirmed, in terms of a thinking curriculum being desirable and "habits of mind" being more important than facts that are quickly forgotten after students leave school. Although thinking was criticised for being so general that it was virtually meaningless, and because teachers were seen to need considerable assistance with both thinking in general and with thinking in each subject, a more positive stance was taken by a small group familiar with teaching young children philosophy.

The learning areas seemed to be what had been expected. The two opposing viewpoints were that the subjects worked against holistic education, and that the subjects were not specific enough to honour the traditional senior-school curriculum. Within the learning areas the notion of a second language seemed to be generally accepted, although some high school subject teachers felt that this would mean they have less time for their specialist subjects. A common observation made about another language was that it was time New Zealand's second official language was given full recognition, although the comment I most enjoyed was about our third official language: sign language. It apparently uses a different side of the brain from spoken languages and therefore helps visual learning, but the opportunities it provides during examinations suggest a wonderful tool for sabotaging the assessment industry.

The learning area descriptors provoked three types of response. Some acknowledged them for being wonderfully brief and as enabling teachers 
to concentrate on what would benefit their students and build on teacher strengths. Others thought the brevity of the descriptors gave little guidance in terms of what was expected. A third perspective was that regardless of what was written, the assessment industry would in fact decide what was taught.

The remarks about effective pedagogy stimulated little response, although one group of teachers I spoke to commented that there seemed to be an assumption of causality between teaching and learning rather than an acknowledgement of the complexity of the learning process.

The notion of designing a school curriculum received a mixed response. Some teachers saw this as a necessary bridge between the official curriculum and the individual teacher's lesson plans, but others asked why they should all have to "reinvent the wheel". The details in this section suggested thematic learning, and while many teachers supported this, others (in particular high school teachers) saw little connection between such themes and the existing assessment requirements.

The outcomes focus for planning and the notion of achievement objectives by levels produced two contrasting viewpoints. Some teachers saw these as sensible and giving a clear indication of what was expected, while others saw them as conflicting with the notions of all students learning "to the best of their abilities" and of all experiencing "a curriculum that makes connection with their lives". Those opposing the outcomes and levels focus seemed to have a more developmental notion of education, although they also expressed the opinion that outcomes were acceptable if they were very broad.

Purposeful assessment stimulated many responses. Formative assessment was seen as valuable, and self-assessment was acknowledged as an important metacognitive skill. But summative and high-stakes assessment were seen as being overemphasised. The notion of an educational system without a high-stakes assessment system for school-leaver qualifications was generally regarded as inconceivable. This suggested to me a lack of awareness of what happens around the world. Assessment was seen by some as being linked with motivation, while others saw it as either demotivating or as replacing intrinsic motivation with extrinsic motivation. 


\section{Curriculum Matters}

Some of the purposes of assessment were seen as being better served by research projects using sampling, while others suggested that the emphasis on assessment indicated a lack of trust of teachers.

The overarching view was that the vision, the principles, the values, and the key competencies are like motherhood and apple pie: they are virtually beyond criticism. However, the reality is that subject content and assessment tend to drive curriculum, and the preliminary pages of a curriculum document usually have little effect on what teachers do.

One further issue that emerged in comments about the draft curriculum relates to what comes after the new curriculum is approved. Professional development initiatives and changes to the focus of assessment were seen as necessary by some, while some level of support for schools where curriculum leadership is needed was also felt to be desirable. Some saw an expansion of advisory services as a way forward, while others hoped that most change would be facilitated at the school level. My personal view is that some form of optional second-level safety-net curriculum would be useful as a basis of ideas for all schools, as a "default" curriculum for schools that feel they lack curriculum development resources or expertise, and as a professional development activity for the teachers involved in developing it.

The most significant reaction to what comes next was that of some of the "half-full" teachers, syndicates, departments, and schools. They had already begun to modify their school curriculum documents and were exploring some of the possibilities that had been implied by the draft document.

I see all curriculum initiatives positively in as much as they give a focus for teachers to re-examine what has often been taken for granted. I favour this particular curriculum initiative because it seems to recognise the right of teachers to make decisions, and it has put more emphasis on the aims of education, even if they are called "key competencies". I am concerned that teachers may react conservatively rather than address the new challenges, and even more concerned that if no change is made to assessment for senior schooling then no change is likely to occur in the enacted curriculum at that level. 
No doubt most of the above viewpoints have been discussed to varying degrees in different schools, and the debate will continue as teachers adjust what they do to fit with the new curriculum. In a similar way, some of these views have emerged in the 11 articles in this year's Curriculum Matters, which focus on a similar range of topics to that of previous issues-areas of curriculum, issues with curriculum, and the development process. The contributors this year have interpreted the word "curriculum" broadly: their interpretations include the official curriculum and the enacted curriculum, and they have acknowledged that curriculum exists at tertiary level as well as in schools and early childhood centres. It has been particularly encouraging this year to see more papers being submitted that are based on thesis work, as curriculum has not been a major focus for educational research in New Zealand in the past, yet it is central to education.

\section{Reference}

Ministry of Education. (2006). The New Zealand curriculum: Draft for consultation 2006. Wellington: Learning Media.

\section{The author}

Andy Begg is the Programme Leader for Postgraduate Education in the School of Education at Auckland University of Technology. His major research interest is curriculum, and this involves the consideration of curriculum documents, the enacted curriculum, and the associated influences on educational development.

Email: andy.begg@aut.ac.nz 